\title{
Do Rational Choice Approaches have Problems?
}

\author{
Wout C. Ultee
}

By analysing examples, this paper makes three points about rational choice approaches within sociology. First, it is maintained that statistical techniques such as path diagrams and log-linear models are more suited to rational choice approaches than is apparent from rational choice criticisms of empirical social research. Secondly, it is held that the conditions under which the postulate that people act rationally is applied are more important than this postulate itself, and that there should be a shift from 'single decision, one good and two actors' to 'multiple decision, three actors and two goods' auxiliary assumptions. Thirdly, it is argued that rational choice approaches pay insufficient attention to the questions they should address and that the sociological tradition might furnish questions leading to exemplars which turn rational choice approaches into a progressive sociological paradigm.

\section{Introduction}

Recently I received a clipping from the Cbronicle of Higber Education on the explanation of Nazi support in Weimar Germany advanced by the sociologist William Brustein. The expression 'rational choice theorist' was underlined, and the coy question 'Are you?' was scribbled in the margin. I flushed.

The query and cut-out - sent by a senior US historian to an apparently still green Dutch sociologist - made me think about what is wrong with sociology. It is not surprising that the press associates an academic with some theory. But why do some scholars identify themselves with one? And why do sociologists who utilize a rational choice approach, define it as so central a part of their self-image? In the 1960 s and 1970 s there were various types of Marxists around, and the more these people identified themselves with theories supposedly proposed by Marx, the better they were at discounting evidence telling against these theories. Is it too much to say that nowadays there are quite a few true believers in the rational choice approach? Theories are devised to answer questions; they ought to be tested, they do not have to be discarded as soon 25 they turn out to be wrong. However, theories do have a record. In sociology it is sometimes necessary to take stock.
I first address arguments holding that rational choice approaches do not square with mainstream research techniques. In my opinion these arguments needlessly discount a prime possibility for testing explanations. I then argue that current opposition to the principle of rational choice is misguided. The pertinent issue concerns the conditions under which it is applied. It should not only be used under the condition that markets prevail. It is also to be applied by making a 'multiple decision, three actors, two goods' auxiliary assumption. My main point is that current rational choice explanations pay insufficient attention to long-standing questions and do not concentrate efforts on a limited set of questions. By drift rather than design, rational choice explanations deal more and more with the social institutions featured in current sociology textbooks, and neglect the questions posed by sociology's founders.

Although I do not identify with one particular rational choice approach, I think rebuttals are as pathological as advocacies, and I agree with proponents of rational choice approaches that sociology is in a sorry state. Homans did not want to be 2ssociated with any tradition except the tradition of telling the truth. I am prepared to contribute to 
every theoretical tradition in sociology having a branch which is guided by a meta-tradition to avoid the immunization of theories against evidence, which values hypotheses for their wealth of information, and judges theories by the problems they solve. My points are that rational choice approaches unnecessarily devalue mainstream empirical social research, pay little attention to interesting auxiliary assumptions while predicting, and would yield more progress by focusing on $2 \mathrm{few}$ long-standing problems rather than by addressing a broad range of hand-picked questions.

Before going on, I wish to say that the expression 'rational choice theory' is somewhat misleading. First, it is not 2 system of hypotheses. It is an approach, or rather a family of approaches. There is Becker's economic approach, which seeks to prove the existence of efficient equilibria. Then there is Boudon's programme highlighting the possibility that individual rationality does not result in 2 collective optimum. One also encounters formal game theory, for instance in the studies by UllmannMargalit. In addition, there are explanations involving historical analysis, such as De Swann's work.

Secondly, it is unclear with which means rational choice programmes are to be executed. The application of general hypotheses involves auxiliary assumptions. Which ones are currently the most promising when applying the principle that people choose rationally? Becker's approach does not stand out so much for the hypothesis that people act rationally, but for the assumption that people act under the condition of the existence of markets. In effect, this programme may be seen as an attempt to turn cultural sociology and organizational sociology into market sociology. However, Boudon's rational choice approach postulates a variety of interaction systems.

Thirdly, what exactly is to be approached with the general hypothesis that people act rationally? Theories are there to answer questions. Which questions are to be tackled within a rational choice approach?

\section{Empirical Social Research Devalued?}

If international sociology has a mainstream, it is empirical social research. Rational choice advocates have been quite negative about some of the statistical techniques of this tradition and of at least one of its substantive show-pieces. Boudon, Coleman, and others are quite right in holding that a causal model does not amount to a theory. Perhaps the concrete hypotheses summarized into causal models can be derived from more general ones, but within the tradition of empirical social research all too often the story behind these models remains untold. Rational choice theorists like longer stories.

A lot of empirical social research seeks to explains variance, and does so by adding factors to some multivariate model. Boudon criticized such factor explanations. It is easy to agree that 2 list of disparate factors is decidedly less worth while than various predictions derived from one overarching principle like that of rationally acting human beings. But how much weight does this argument have against the application of multivariate models?

A perusal of the literature falling within the tradition of empirical social research makes clear that quite a few of the research questions do not amount to explaining variance in one variable, but to explaining the association between two variables. In my opinion, the more of these questions, the better. However, the explanation of empirical regularities does not do away with multivariate models. In that case, what should be considered is not so much the percentage of explained variance in some dependent variable, but the proportion of the association between two specific factors accounted for after inserting into a bivariate model factors central to the proposed explanation of this association. If it is a rational choice explanation, these factors involve the preferences of individuals and the resources they command and barriers they face. My point is that a focus on the proportion of explained association makes Lazarsfeld's elaboration procedures for tabular analysis appropriate. Also pertinent is path modelling, a type of multivariate linear regression. But path models have been held to be less useful for testing rational choice explanations. One instance is Boudon's criticism of Duncan's path model of the socio-economic life-cycle. To determine the force of Boudon's criticism, let me recount the story behind Duncan's model.

First-generation social mobility studies sought to determine how much difference there is in social mobility between industrial countries and the extent 
to which these differences are explained by the survival of feudal traditions, the nature of the party wielding power over the state, and the pace of economic development. Research of the second generation - Duncan's path model of the socioeconomic life-cycle was its exemplar - postulated that in agrarian societies the relation between father's and son's occupation largely results from direct transmission. In industrial societies the relation between father's and son's occupation is weaker. This link itself was to be accounted for by the effect of father's occupation on son's education (which weakened) and the bond between son's education on occupation (which strengthened). With modernity, there was a shift from ascription to achievement in the socio-economic life-cycle of individuals. A test of this hypothesis from the functionalist approach within mainstream sociology involves a comparison of at least two path models of the socio-economic life-cycle. Duncan compared four (Blau and Duncan, 1967: 181).

Thus, status attainment models explain the positive association occurring in a certain country at a certain time between father's and son's occupation. They do so by invoking education not simply as an additional factor, but 28 a resource which at various times is transferred in different degrees from father to son and which is more powerful in some periods than in others. Of course, the hypotheses about the link between origin and education and between education and occupation in their turn might be explained. But an unqualified demand for explanation results in an endless story. Models of the socioeconomic life-cycle terminate the explanation of a regularity by invoking the material and cultural constraints faced by parents making educational decisions for their children, and the choices employers make when selecting employees. Indeed, the prevalence in industrial societies of achievement values so often asserted by functionalism may be viewed as the existence of laws stipulating freedoms available to anyone, such as those of education, enterprise, and residence, plus values shared by the population supportive of these universal freedoms. Path models stop explaining an empirical regularity at a point congenial to rational choice programmes.

In the course of the second generation of mobility research it gradually became clear that the shift from a distributive process governed by particularist ascriptive values to one guided by universalist achievement values was at least not as fast as had been predicted. New explanations were proposed that explained these persistent inequalities. One was advanced by Boudon. Schooling had expanded rapidly in Western industrial nations in the period after World War II, but social mobility had hardly increased and was occurring to more or less the same degree in most industrial societies. That is, although according to models of the socioeconomic life-cycle the more highly schooled members of a certain population have the better jobs, in societies with a higher average level of schooling social mobility was not more widespread. Boudon (1973) held that regression models were inadequate to capture the processes of reproduction occurring in societies. To what extent is this a valid criticism?

Boudon's criticism of the model of status attainment was not teally that it did away with people making choices. A model of status attainment assumes that when explaining a person's level of education, the auxiliary assumption of one choice suffices: 2 big one-shot choice between each and every institutionally possible level of education. Boudon's idea was that there are in an educational system several points at which decisions whether or not to continue studying are being taken, and that the outcomes of these decisions combine to represent the variable 'finally attained level of education'. In this way, small inequalities in the chances of continuation between the children from different social background at the various branching points in 2 schooling system result in large social inequalities in the total level of schooling. According to Boudon, this process cannot be modelled by linear regression techniques.

Mare (1980) addressed the question of explaining the relation between social origins and final education as the combined result of several decisions. He found that stable odds ratios for persons from a higher rather than a lower social origin for each decision to stop or to continue studying, together with educational expansion and more equal ratios for later decisions, at the aggregate level logically imply 2 weakening of the tie between sorial origins and total years of schooling. The technique Mare applied for modelling the various transitions was, given the series of yes-no choices, logistic regression for each choice and linear regression for the 
combined outcome. Boudon left unclear whether his remarks about techniques that do not accord with modelling multiple decisions applied to all kinds of regression techniques or only to linear regression and path analysis. A test of Boudon's explanation turned out to involve logistic regression models.

Some years after Boudon's criticism of the socioeconomic life-cycle, research on social mobility entered a third generation. For a long time those working in this field had struggled with complementing the total percentage of persons mobile in a society from one stratum to another, with 2 measure that indicates how much circulation or exchange there is between a society's strata. In the second half of the 1970s this measure was found in odds ratios and parameters from log-linear models. Goldthorpe (1980: 77) gave its most effective formulation. The old question about circulation mobility was to be rephrased as one about competitions: an odds ratio can be interpreted as indicating the degree of inequality in the outcome of a competition between persons from one rather than another social origin for one rather than another destination. Later it became clear that it was not only the competitive outcomes that could be captured by log-linear models for the interior cells of 2 mobility table. The degree of (un)favourableness of structures in which various competitions take place could also be represented by log-linear parameters, in this case for the marginals of square tables. One example of such a structure is the number of higher positions available in a labour market compared with the number of persons from higher origins. Another pertains to marriage markets and the number of men with university education marrying in a certain year relative to the number of women with that level of education who do so.

The difficulty of devising measures for competitive outcomes before the onset of the third generation of mobility studies was often phrased as the need to eliminate structurally enforced mobility from total mobility, with the structures forcing mobility being represented by the marginals of a mobility table. This second generation formulation was criticized by Coleman (1987). Coleman maintained that an approach 2ssuming that the choices of individuals are constrained by structures does not eliminate their effects. Rather, it determines their influence upon the choices of individuals. This criticism holds that path models of the socioeconomic life-cycle are not suited to the explanation to be tested. Because these models involve the computation of standardized regression coefficients, they do away with structures. They should incorporate the effects of structures.

Coleman's criticism against standardized linear regression is powerful. However, it makes unstandardized linear regression more attractive: the intercept of an equation regressing son's unstandardized occupation on father's unstandardized occupation represents structural mobility (McClendon, 1977). But how do Coleman's arguments affect log-linear models? To begin with, mobility purged of marginal effects may itself be seen as an aspect of society's structure. Following Blau (1977), a structure is not only made up of a distribution. It also involves the relation between a person's place in one distribution and that person's place in another distribution. Secondly, log-linear models are able to capture the extent of discrepancies between marginal distributions. Thirdly, some hypotheses about structural effects lack substance. The hypothesis that women at a marriageable age from cohorts with a sex ratio that is unfavourable to them are more likely to remain unmarried or to marry older men is tautologous. Finally, models with parameters pertaining to competitions between people differing in resources are quite well suited to theories that assume that people act rationally and under the constraints of markets.

Coleman voiced another criticism of models of the socio-economic life-cycle. He is concerned with the issue of how to answer macro-questions by micro-hypotheses, and regards Duncan's models as one instance where it was ducked. To make his argument, Coleman made a diagram consisting of four dots connected by lines, with the lower horizontal line standing for a relation between two individual variables and the upper one for a relation between two macro-variables. According to Coleman, Duncan's story about the socio-economic life-cycle leaves the line going down from the macro-level to one individual variable unspecified, as well as the line going up from the individual variable to the macro-level.

Is this really so? The bond between the social origin of persons and their social destination is not 
only an individual relation. It is also a characteristic at the macro-level. Of course, one model of the socio-economic life-cycle does not yield a macrovariable. But then, Duncan made models for four cohorts of US males. An odds ratio or a log-linear parameter aggregates individual data into measures of the unequal outcomes of competitions between individuals. Erikson and Goldthorpe (1992) compared such measures for 2 dozen countries.

Mobility studies explain the strength of the relation between father's and son's occupation occurring in a society at various points in time. Thus, the lower horizontal line in Coleman's diagram can be viewed not only as an individual relation, but also as a macro-phenomenon. Coleman's diagram does not help in making this Gestalt switch. The diagram is misleading because it involves only one model of the socio-economic life-cycle. It must be added that structural effects can be estimated by incorporating variables for them (for instance the average level of education attained in various cohorts) into linear and logistic regression equations. In the past few years multi-level modelling has blossomed. If, for instance, a linear regression model includes an effect of a structural variable on the slope of the regression of father's occupation on son's occupation, macro is linked to micro and micro to macro.

\section{'Do People Behave Rationally or is their Behaviour Guided by Norms?' and Other Folse Questions}

In sociology it is accepted that theories should be multi-layered (Homans, 1967; Lenski, 1988): a hypothesis explaining an empirical regularity can, in its turn, be explained by 2 higher-level one. When applying this stipulation, the question arises of how far one should press explanations and what the highest level looks like. It has been held for 2 long time that sociology should explain regularities pertaining to societies, but that their explanation should refer to individuals. More recently it has been held that explanations should involve the assumption that individuals act rationally. In fact, 2 rational choice approach is stricter than methodological individualism. Indeed, Becker's approach is even stricter - on two counts.
The argument that (rational) individual explanations amount to higher-level explanations is convincing as a logical exercise. However, it has to be pointed out that higher levels of generality can be obtained not only by moving from the macroto the micro-level, but also from more specific phenomena on the macro-level to more abstract phenomena on that level. The example of Lenski's ecological evolutionism suggests that both movements are present in elaborate answers to macrosociological questions (Lenski, 1966; Lenski et al., 1995; cf. Ultee et al., 1992). Thus, the question of whether progress is to be made by going after higher-level explanations on the micro- rather than on the macro-level, is a loaded one.

The case in favour of higher-level explanations in the social sciences has been argued most succinctly by Malewski (1967). It is worthwhile to develop a higher-level explanation because it corrects a lowerlevel one or an empirical regularity. It does so by indicating conditions under which the lower-level explanation does not hold or the empirical regularity does not obtain. The logic of this argument is faultless; its force is unknown. As a logical argument it does not and cannot say how often these conditions occur.

Wippler (1983) derived conditions under which Michels's iron law of oligarchy does not hold: a trend towards oligarchy in a voluntary organization is not irreversible, but depends on conditions that may not always obtain. One of them is the existence of other voluntary organizations catering to the same needs of the same persons. When an organization's leaders do not respond to rank and file pressure, its members may not only become inactive because voicing one's opinion goes unrewarded, but may quit and form a new organization. That is certainly possible. But quite probably the costs of starting a new organization are higher than the costs of raising one's voice within the old one. And the rewards of the new organization are only potential and distant. So, how often will dissatisfied members quit an organization to start a new one? The question of the conditions under which an empirical regularity or a lower-level explanation holds is not very relevant. A distinction has to be made between more and less frequently occurring conditions.

In recent debates on what exactly the highest level of explanation should be like, the principle of rational 
choice has been contrasted with the principle of norm-guided behaviour. This occurred in exchanges on Dahrendorf's bomo sociologiews and Becker's bomo eronomicus, and in empirical studies explaining specific empirical regularities. Friedman (1983) tests normative explanations of religious specialization in academia against rational explanations. According to Heath et al. (1991) in the field of voting behaviour there are economic and social explanations.

In my opinion, this debate presents a false dichotomy. If contrasts are to be made, it is between the assumption that the actions of individuals take place within markets and the assumption that they take place under other conditions. According to Heilbroner (1953), the discovery of classical economics was not that of a rational human being. Its contribution was the hypothesis that under the condition of markets self-interest leads to a greater improvement in general welfare than under the condition of organizations and traditions. Markets, organizations, and traditions are co-ordinating mechanisms. In markets, behaviour beneficial to the commonwealth is elicited by the lure of higher profits, wages, and rents. In organizations dysfunctional behaviour is warded off by the threat of physical sanctions. Networks make people follow traditions by admiration and humiliation. But under all three conditions human behaviour is selfinterested and rational.

Becker's predictions only apply in those cases where markets prevail: 'The economic approach has been refined during the past two hundred years. It now assumes that individuals maximize their utility from basic preferences that do not change rapidly over time, and that the behaviour of different individuals is coordinated by explicit or implicit markets' (Becker, 1981: ir). Compared with the stipulation that social phenomena should be explained by the rationality of actors, Becker makes two additional demands on highest-level explanations. First, they should not assume that preferences change (nor that they differ between individuals (Stigler and Becker, 1977)); they invoke at most differences in the resources people command and the barriers people face. That is why the label 'constrained choice approach' is more appropriate than 'rational choice approach'. Secondly, the only interaction system referred to in an explanation should be of the market type.
Many a sociological criticism of the economic approach has been directed against the assumption of utility maximization. Berger (1992) pleaded in favour of Pareto's thesis of non-logical behaviour. However, the assumption that people act irrationally does not lead to definite predictions. In this sense, a rational choice approach is simply a rational choice. The contemporary issue of the yield of a full rationality approach versus a limited rationality approach will be left untouched here. In my opinion, experimental psychology does not yet allow for substituting one postulate for another.

A second criticism of Becker's economic approach is directed at its auxiliary assumptions on preferences. Van Pra2g and Kapteyn's (1973) evidence in favour of reference drift and habit formation is quite convincing. Their hypotheses are also quite useful because the arguments of rational choice proponents are often directed against the ad bor character of many studies postulating changing or differing preferences. This argument certainly does not apply to Van Pragg and Kapteyn's hypotheses. What is more, the criticism of that they are ad boc might apply to assumptions about resources: it undoubtedly applies to Bourdieu's (1987) assumptions on various forms of capital.

Thirdly, it is not clear why an economic approach should assume the omnipresence of markets. Certainly, the commands of an organization are often disobeyed, and in certain cases no commands exist. In addition, not everything is ritualized, and traditions can vary in the extent to which people live up to them. But then, each freedom of the market is not invoked by everyone, and societies vary in the extent to which people have the right to do whatever they like. In addition, a model of the whip of authority seems as simple as a model of the lure of market gains, and so does a model of the strait-jacket of tradition.

Finally, Becker's auxiliary 2ssumption of the preponderance of markets clashes with the thrust of the sociological tradition. Weber's and Durkheim's studies exemplify the crudeness of the assumption that markets prevail for the study of contemporary societies and its unsuitability for the study of longterm social changes, a prime topic for macro-sociological research. It even is doubtful whether the assumption of a shift in co-ordinating mechanisms from organizations and traditions to markets is 
accurate enough to get a grip on long-standing questions. As first Weber, and later Elias, made clear, the rise of the West is seen not only in the advent of markets, but also in the rise of one specific type of organization. That organization possesses 2 near-monopoly on the means of violence and is called the state. As Coleman (1982) implied, for the study of contemporary societies the notion of an actor should be expanded so as to include corporate actors. In addition, empirical social research on consumer choice in contemporary Western societies undertaken by Lazarsfeld and his pupils has shown the effects of traditions enforced within networks. It has led to Coleman's (1988) hypothesis that social capital contributes to the creation of human capital.

Of course, currently there are varieties of rational choice approaches which are more liberal than Becker's approach to the issue of the conditions under which the principle of rational human beings is to be applied. One of them is Boudon's programme. It contains the assumption that human behaviour is constrained by interaction systems, and two types of such systems are distinguished: functional systems and systems of interdependence. These systems are not clearly delineated. However, it is obvious that Boudon's functional systems, in which individuals play roles, are traditional or organizational, and that systems of interdependence, from which roles are absent, are akin to markets. It is also clear that Boudon has hypotheses on markets that are different from Becker's. In Boudon's markets the number of persons with higher levels of education may be persistently higher than the number of jobs requiring these levels. Under such circumstances, rational employers will choose not only on the basis of education, but also on the basis of social origins. This makes for $a$ reproductive process precisely because of educational growth.

The difficulty for more liberal rational choice programmes is exactly their libertarianism. The rule to apply the auxiliary assumption of the existence of markets, organizations, or traditions as seems fit, makes for ad boc theorizing. The injunction to depart from $2 n$ interplay of rights, duties, and prohibitions, does not help much either. In fact in the current situation of theorizing, the choice between market, organization, and tradition is not the most pressing one. I have already referred to Boudon's rule when formulating auxiliary assumptions, to view a seemingly one-shot choice as a multiple decision. Another rule says that the explanation of a phenomenon is furthered by assuming that people do not strive after one good, but after several. I will discuss this rule in the next section. A third rule, which holds that the common auxiliary assumption of two actors should be replaced by an assumption of three actors, will be elucidated now. I thus maintain that the highest-level principle that people act rationally should not be applied under a 'single decision, one good, and two actors' auxiliary assumption, but under 2 'multiple decision, three actors, and two goods' assumption.

Let the compare Becker's (1968) explanation of crime with Merton's (1938) anomie theory. In the economic explanation of crime, a certain form of behaviour with a certain probability meets a punishment of some severity. People will perform this behaviour when its yield surpasses the probability of punishment multiplied by the severity of punishment. There are well-known exceptions to this explanation. How are they to be explained? In my opinion it should be recognized that the economic explanation is a two-actor explanation. The explanation is a two-actor one because there is a natural person who will or will not trespass the law, and a corporate actor who punishes violations of the law with a certain probability and severity.

Merton seeks to account for the finding that throughout the past decades relatively more persons committed crimes in the United States than in some European countries. Merton's story is not that crime is punished less severely or less frequently in the United States. One novel feature of Merton's theory of anomie is that it invokes a third actor: a general public that shuns people who do not pursue material benefit and applauds those who succeed. In that case there is a social incentive for a person lacking the legitimate means necessary for obtaining material goods, to use illegitimate means. The fruits of crime are applauded more in the United States than in Europe.

Of course, Merton's three-actor explanation has not fared that well in empirical research. But anyone interested in advancing a rational choice approach to phenomena other than crime should consider that two-actor explanations might be improved by three-actor ones. Promising explanations invoke 
several kinds of actors using different types of sanctions.

\section{Rational Choice Questions and Sociology's Questions}

What exactly is to be approached within a rational choice framework? Theories are there to answer questions and to solve problems. We need to explore which problems have been targeted by rational choice approaches. Questions like those of Ullmann-Margalit (1977) on the emergence of norms are derivative - just like questions on the emergence of markets. What are the prime problems?

Nowadays it is generally accepted that sociology does not have a core of questions all its own. According to Berger (1992), sociology does not have a subject, only an approach. According to Gove (1995), sociologists are concerned with a heterogenous list of topics, and Davis (1994) agrees. Boudon (1979) also holds that sociology cannot be defined by listing its questions. Such opinions make it easy to make inroads into sociology. Each rational choice programme is given a freedom to pick questions. Are easy questions being addressed or long-standing ones?

Friedman and Hechter (1988) list macro-sociological questions to which a rational choice approach might fruitfully be spplied. On two counts, their list is not persuasive. First, the more interesting questions from a formal point of view are those that pinpoint a contradiction between some empirical finding and some hypothesis. At least, this is the first rule of the rational choice approach taken by Boudon (1979; see also Popper, 1962). Now it is known that rational choice approaches face anomalies. Some of them are mentioned by Friedman and Hechter, but the way they might be digested is spelled out less fully than the way a rational choice approach might deal with anomalies for other approaches. Secondly, it does not really do to point towards anomalies for other approaches that might be resolved within a rational choice approach. Listing such anomalies is like fishing in a rich pond. How many anomalies still float around freely?

In recent years the application of programmes of rational choice to sociological questions seems to have been following the definition of sociology in American textbooks. This stipulation holds that sociology is concerned with societies, and that societies consist of various institutions. One such institution is the economy, and various aspects of it have already been covered by a rational choice approach in the form of neoclassical economics. Another institution is the polity, and, since Schumpeter and Downs, at least some social scientists concerned with politics have used a rational choice framework. Then there is the judiciary as an institution. Here work within criminology following Beccario and Bentham is relevant. This leaves sociology as dealing with the family and religion as institutions.

What does the new household economics seek to explain about the family? Becker (1981: ix) says: 'This book contains an economic approach to the family, not in the sense of an emphasis on the material aspects of family life, but in the sense of a particular theoretical framework for analyzing many aspects of family life.' These aspects turn out to be marriage, birth, divorce, and the division of labour within households. However, explaining aspects is not the same as raising questions about empirical regularities. It is often unclear exactly which empirical regularity occurring somewhere sometimes is to be explained. Whereas Boudon's programme held that sociology should explain social phenomena that are puzzling given simple applications of the principle that human beings act rationally, Becker's approach does not seem to follow such a rule for picking questions. At a time when the tendency for married women to work outside the home was increasing, this approach made it plausible that people married to each other and maximizing their utility, would work out some division of labour. Assortative marriage is a well-known regularity. Becker predicts complementarity rather than similarity, and says that sociologists have not done empirical research on his kind of complementarity.

Thus my criticism is not that current economic explanations are wanting; it is that they deal with the less interesting questions. Goode (1974) remarked that the possibility that some men profit from having several wives does not explain why polygyny occurs in some places and not in others, especially if we know that if polygyny is allowed one man typically takes one woman: 'Why are such 
systems approved and viewed as an ideal, though few can attain it?' It may also be asked to what extent questions about the family may be turned into questions about the effects of behaviour taking place within markets. To what extent is the expression 'marriage market' more than a metaphor? In contrast to Becker, Coleman (1987) has dealt with marriage squeezes. Apparently strong inelasticities occur in marriage markets. What effects do such competitive structures have on the extent of assortative marriage occurring in societies? These arguments generate more questions than those on the effects of the existence of marriage markets for efficient equilibria. And perhaps these other questions are more interesting because they are concerned with societal cohesion as indicated, for instance, by non-assortative marriages.

Stark's rational choice explanations of religious phenomena explicitly seek to account for phenomena pinned down to a particular place and time. If religion offers rewards like care for the sick, new religions should arise in times of large epidemics. According to Stark's (1992) analysis of early Christianity, this is the case. But why does this rational choice explanation of religion lead to a question about the rise of Christianity? The question of whether Christianity arose in times of epidemic seems a logically easy choice - and one not conducive to strong empirical tests. Stark's specific application of rational choice principles says that religion is to be explained by starting from epidemics. Thus the question is not: 'Did the rise of religion $X$ take place in times of some epidemic?' The question implied by the argument is: 'Did epidemic $X$ prompt a new religion which offered more support in times of illness than existing ones?' If that is the case, there is no necessity to go back to diseases in other countries in far away times when there is AIDS in the USA today. In addition, as far as common knowledge of the religious consequences of the medieval plague goes, this disease gave rise not so much to a new religion as to hatred against Jews. What kind of support does this offer to the sick?

Another of Starks explanations does deal with a long-standing and interesting question. According to Nisbet's (1966) rendition of the sociological tradition, the industrial and democratic revolutions would effect a change from the sacred to the profane. However as research shows, in the USA - the most economically developed country in the world and a country with strongly developed democratic institutions - secularization, as measured by a low frequency of church-going and a low percentage of people believing in God, is quite weak and barely increasing. Why is there so little secularization in the USA? According to Stark and Iannaccone (1994), competition between the various religions is much stronger in the USA than in Europe, with its history of state churches. This competition would improve the goods on offer, and increase church attendance and belief in God.

However, Stark's specification of this question by 2 rational choice perspective remains somewhat unsatisfactory. The hypothesis of industrialism and secularization is not to be rejected outright, but has to be included in and conditioned by an overarching explanation. The sociological tradition holds that secularization increases because religious institutions not only offer salvation hereafter but also give support in times of illness, with disease in industrial societies being viewed as to a large extent under human control through medicine. With respect to the provision of health, in contemporary societies preachers compete not only with one another, but also with doctors. Do churches in Europe get more competition from hospitals than churches in the USA, for instance, because European states provide to a larger extent for the health of their citizens? I would suggest that novel applications of the principle of rational choice to religious institutions assume that churches deliver salvation plus some less obvious good, and that bringing in the latter good increases the number of suppliers by postulating a new type of competitor. By consequently applying a two-goods rule, rational choice questions become more imaginative.

At present, rational choice programmes are beginning to address long-standing and original questions about families and religions. If they are to make progress they also have to deal with the large questions raised by the founders of sociology. When reviewing them, it turns out that they comprise several smaller questions under one heading (Ultee, 1991). For that reason I hold that-contrary to various recent pronouncements - sociology has central problems: problems of rationalization (Weber), of inequalities (Marr), and of societal cohesion (Durkheim). These questions are to be 
understood as questions which, at least in days gone by, were not adequately addressed by economics.

Adam Smith, the founder of economics, focused on the wealth of nations. Weber held that the wealth of Western nations could not be fully explained by the formation of markets, that is by the emergence of the rights to free enterprise and free labour. These rules provide people with opportunities, but these will not be used unless there is a motivation to use them. According to Weber, at first people did not use these rights because they were lured by higher profits and wages. They pursued another goal. If God placed them on earth to honour Him not only in their prayers but also in their labour, they should not be content with what they had, but should seek to improve their station in life. Since Protestants invented this world-view, Protestants used the freedoms of enterprise and labour more than Catholics did.

Following Weber, classical economics did not raise the question of whether there were other motivations than a higher standard of living which make people use their legal economic rights and increase the wealth of nations. Nor does contemporary institutional economics often do so. North and Thomas (1973) argued that the emergence of intellectual property rights was more important in the rise of the West than the emergence of other freedoms. Their study simply avoided the question of whether different kinds of people are equally likely to use these rights. Let me add that the sociological tradition does not require yet another study on the difference between Protestantism and Catholicism. The question rational choice approaches have to deal with is that of whether all inhabitants of a society are equally motivated to use their economic rights.

Weber held that the rise of the West relied not only on the advent of markets, but also on the rise of bureaucracies, regarding both as instances of rationalization processes. Here the sociological tradition must be faulted for postulating the formal state without explaining its rise. What is more, De Swaan's historically inclined rational choice approach is to be praised for improving upon Weber's articulation of the problem of the state. Following Weber, the state has the legitimate monopoly on violence and taxation. So what are taxes being spent on? Only on armies, courts, the police, and prisons? Certainly not. De Swa2n (1988) combined the assumption that armies, courts, the police, and prisons are collective goods for the inhabitants of a country, and the hypothesis of welfare economics that states limit externalities, into a research programme.

De Swaan's programme is guided by an overarching problem comprising various sub-questions. Viewing a person's poverty, illiteracy, illness, and unemployment as phenomena which have negative external effects for the other inhabitants of a state, De Swaan broke the problem of the provision of collective goods in general down into that of explaining how municipalities, provinces, and states came to erect workhouses, to build schools and make attendance compulsory, to counter epidemics with piped water and sewerage, and to insure people against the vagaries of the labour market. By bringing in welfare economics, De Swaan improved upon Weber's problem of bureaucracy.

Smith held that the advent of the market improves almost everyones standard of living. The Marxist programme in sociology, following the leads provided by Ferguson and Ricardo, raised the question of inequality: the standard of living of the well-off might be increased more by the rise of markets than the standard of living of the truly disadvantaged. In addition, sociology, more than economics, regards the problem of income disparities as only one subproblem of an overarching problem of inequality. If a country's income distribution remains the same, this does not mean that all inhabitants stay put. One specific degree of income inequality is compatible with various amounts of mobility by individuals from one income category to another. Social mobility is a long-standing question in sociology, and less unequal outcomes of competitions between persons from higher rather than lower origins for higher rather than lower destinations decrease long-run inequalities. With its interest in questions of assortative marriage, sociology also studies another sub-question of the inequality problem. If random mating occurs in 2 country where both spouses have incomes, inequality between households will be smaller than in 2 society where like marries like.

Of course, contemporary neoclassical economics attempts to explain disparities in a country's personal income distribution. Interestingly, such theories as those of Thurow on job rather than 
wage competition and Lindbeck on insiders and outsiders, have not gained the approval furnished by the label 'rational choice approach'. They do not assume markets, but study the effects of other regulations. Becker's chapters on intergenerational mobility and assortative marriage are best understood as admitting that these phenomena are to be explained by an empirically successful economic approach.

Societal cohesion is sociology's third major problem. Following Hobbes, the founder of the utilitarian tradition of which rational choice approaches are an offshoot, the war of all against all indicates the absence of societal cohesion. This is true but obvious. Durkheim maintained that the problem of cohesion was more general than that of strife and peace, and his formulation of the problem of societal cohesion also embraced less obvious indicators, such as weak social bonds, with suicide as an extreme case. In fact, Durkheim held that if markets make for the greatest happiness of the greatest number, suicide in France should have decreased during the nineteenth century. In fact, it increased. According to Durkheim the suicide rate rose because the emergence of markets by definition amounts to the disappearance of intermediary groups, and because integration in intermediary groups lowers the chances of suicide.

Since Hamermesh and Soss's (1974) economic theory of suicide, rational choice approaches have not contributed much to solving this less obvious part of the problem of societal cohesion. In fact, the question this theory sought to answer was not about well-known regularities in suicide statistics at all. Hechter faced the problem of cohesion, or rather solidarity, head on. Although the problem of cohesion has been divided within the sociological tradition into various sub-questions, Hechter (1987: 19) surprisingly maintains that it is difficult to find convincing indicators of solidarity. Hobbes would have said that a society displays more solidarity if the murder rate is lower, and Durkheim if the suicide rate is lower. Hechter settles for the average proportion of a person's private resources contributed to collective ends. These resources are not only money (the amount of money spent on a Christmas present for a spouse), but also time (the proportion of faculty members attending a funeral service for a deceased faculty member). It remains unclear why
Hechter does not invoke the language people use when speaking about others: they may use kind words or utter abuse. It certainly is possible to regard language as the resource characteristic of human beings. My point here is that, in defining solidarity in this way, Hechter seems to ignore such pertinent questions as the extent to which time spent on drinking coffee with friends makes for more support in times of illness, how far charity reduces the threat to public safety from itinerant beggars, and whether parental explanations rather than dictates lower the probability that children hurt others. The specific sub-questions of the problem of cohesion as posed within the sociological tradition have disappeared behind the horizon.

So let me sum up by challenging proponents of 2 rational choice approach to take the main questions of the sociological tradition and their sub-questions seriously. Of course, this tradition does not offer a list of neat research questions. But it does point towards certain types of interesting questions. And it might lend more coherence to a programme that deals with so many loosely related questions that it says something about nearly everything while making progress with almost nothing.

\section{Conclusion}

Lenski (1966: 40-1), when addressing the question of inequality, stated:

unlike the classical economists we cannot limit ourselves to those exchanges which are legal, ethical and peaceable. We must concern ourselves with both the legal and illegal, the ethical and the unethical, the perceable and the violent. Were we to limit ourselves to those exchanges which are legal, ethical and peaceable, we should arrive at quite a misleading answer to the question of who gets what and why. ... That is why the classical economists have managed to shed so little light on the question of who gets what and why, despite the fact that they have written voluminously on the subject of distribution.

Does 2 statement like this apply to the same extent to rational choice approaches within contemporary sociology? 
Of course, the conclusion of a paper is no place to provide a full answer to such a broad question. But as my argument has indicated, there are grounds for pessimism. So let me finish on an upbeat note with three signs of hope. First, current techniques of statistical analysis are more attuned to rational choice explanations than has been supposed. Secondly, if progress is to be made in deriving novel predictions from the assumption that people act rationally, this principle should not only be applied under a 'single decision, one good, two actors' auxiliary assumption. Auxiliary assumptions should also invoke a 'multiple decision, three actors, and two goods' assumption. Thirdly, rational choice approaches are in need of exemplars for puzzlesolving. The sociological tradition might furnish interesting questions leading to persuasive exemplars.

\section{References}

Becker, G. S. (1968) Crime and punishment: an economic approsch. Joxrnal of Political Economy, 76, 169-217.

Becker, G. S. (1981) A Treatise on the Famib. Harvard University Press, Cambridge, Mass.

Berger, P. L. (1992) Sociology: a disinvitation? Soriety, 30, 12-18.

Blau, P. M. (1977) Inequality and Heterogencity. Free Press, New York.

Blau, P. M. and Duncan, O. D. (1967) Tbe American Occupational Structure. Wiley, New York.

Boudon, R. (1973) L'intgalité des chances. Armand, Paris.

Boudon, R. (1979) La logigu dusacial. Hachette, Paris.

Bourdieu, P. (1987) The forms of capital. In Richardson, J. G. (ed.) Tbe Handbook of Tbeory and Ressarcb for the Sociology of Education. Greenwood Press, New York.

Coleman, J. S. (1982) Tbe Asymmetric Sacioty. Syracuse University Press, Syracuse, NY.

Colemen, J. S. (1987) Microfoundations and macrosocial behavior. In Alexander, J., Giesen, B., Munch, R., and Smelser, N. J. (eds.) Tbe Micro-Marro Link. University of California Press, Berkeley.

Coleman, J. S. (1988) Social capital in the creation of human capital. American Jowrmal of Saciolog, 94, S94S120.

Davis, J. A. (1994) What's wrong with sociology? Sariological Forwe, 9, 179-97.

De Swaan, A. (1988) In Care of tbe State. Polity, Cambridge.

Erikson, R. and Goldthorpe, J. (1992) Tbe Constant F/ux. Clarendon Press, Oxford.
Friedman, D. (1983) Normative and rational explanations of a classic case: religious specialization in academia. In Hechter, M. (ed.) Tbe Microfoundations of Macrosaciology. Temple University Press, Philadelphia.

Friedmen, D. and Hechter, M. (1988) The contribution of rational choice theory to macrosociological research. Sariological Tbeory, 6, 201-18.

Goldthorpe, J. H. (1980) Sacial Mability and Cless Structure in Madern Britain. Clarendon Press, Oxford.

Goode, W. J. (1974) Comments: the economics of nonmonetary variables. Jamornal of Political Esonomy, 82, 527-33.

Gove, W. R. (1995) Is sociology the integrative discipline in the study of human behavior? Sorial Forces, 73, 1197-206.

Hamermesh, D. S. and Soss, N. M. (1974) An economic theory of suicide. Jommal of Political Economy, 82, 83-99.

Heath, A., Jowell, R., Curtice, J., Evans, G., Field, J., and Witherspoon, S. (1991) Understanding Political Cbange. Pergamon Press, Oxford.

Hechter, M. (1987) Principles of Groxp Solidarity. University of California Press, Berkeley.

Heilbroner, R. L. (1953) Tbe Worldly Pbilosopbers. Simon and Schuster, New York.

Homans, G. C. (1967) Tbe Natwre of Sarial Sciense. Harbinger, New York.

Lenski, G. (1966) Power and Privilge, A Tbeory of Sacial Stratification. McGraw-Hill, New York.

Lenski, G. (1988) Rethinking macrosociological theory. A werican Saciological Reviow, 53, 163-71.

Lenski, G., Nolan, P., and Lenski, J. (1995) Human Societies, 7th edn. McGraw-Hill, New York.

McClendon, M. J. (1977) Structural and exchange components of vertical mobility. A merican Sariological Rrvios, 42, 56-74.

Malewski, A. (1967) Verbalten send Interatetion, Dis Theoris des Verbaltens end das Problem der soqialvissenscbaftlicben Integration. Mohr, Tubingen.

Mare, R. D. (1980) Social background and school continuation decisions. Jowrnal of the American Statistical A ssaciation, 75, 295-305.

Merton, R. K. (1938) Social structure and anomie. American Saciological Review, 3, 672-82.

Nisbet, R. A. (1966) The Saciological Tradition. Basic Books, New York.

North, D. C. and Thomas, R. P. (1973) Tbe Rise of tbe Westerm World. Cambridge University Press, Cambridge.

Popper, K. R. (1962) Die Logik der Sozial wissenschaften. Köhner Zeitsebrift fir Soziologie and Sozialpgebologie, 14, 233-48.

Stark, R. (1992) Epidemics, networks, and the rise of Christianity. Semeia, 56, 159-75. 
Stark, R. and Iannaccone, L. R. (1994) A supply-side reinterpretation of the 'secularization' of Europe. Jawrmal for tbe Scientific Study of Religion, 33, 230-52.

Stigler, G. J. and Becker, G. S. (1977) De gustibus non est disputandum. American Ecososwic Review, 67, 76-90.

Ullmann-Margalit, E. (1977) Tbe Emergance of Norms. Oxford University Press, Oxford.

Ultee, W. (1991) How classical questions were enriched. In Becker, H. A., Leeuw, F. L., and Verrips, K. (eds) In Purswit of Progress: $A n$ Assessment of Acbiovenents in Dutcb Saciology. Siswo, Amsterdam.

Ultee, W., Arts, W., and Flap, H. (1992) Saciologie. vragen, witspraken, bevindingen, Wolters-Noordhoff, Groningen.

Van Praag, B. M. S. and Kapteyn, A. (1973) Further evidence on the individual welfare function of income. Europear Exonomic Review, 4, 33-62.
Wippler, R. (1983) Een model van oligarchiseringsprocessen in democratische organisaties. In Lindenberg, S. and Stokman, F. N. (eds.) Madellen in de saciologie. Van Loghum Slaterus, Deventer.

\section{Author's Address}

Department of Sociology, Faculty of Social Sciences, University of Nijmegen, PO Bor 9104, $6500 \mathrm{HE}$ Nijmegen, The Netherlands. E-mail: w.ultee@maw. kun.nl.

Manuscript received: December 1995 